\title{
Important Observations and Parameters for a Salt Water Intrusion Model
}

by W. Barclay Shoemaker ${ }^{1}$

\begin{abstract}
Sensitivity analysis with a density-dependent ground water flow simulator can provide insight and understanding of salt water intrusion calibration problems far beyond what is possible through intuitive analysis alone. Five simple experimental simulations presented here demonstrate this point. Results show that dispersivity is a very important parameter for reproducing a steady-state distribution of hydraulic head, salinity, and flow in the transition zone between fresh water and salt water in a coastal aquifer system. When estimating dispersivity, the following conclusions can be drawn about the data types and locations considered. (1) The "toe" of the transition zone is the most effective location for hydraulic head and salinity observations. (2) Areas near the coastline where submarine ground water discharge occurs are the most effective locations for flow observations. (3) Salinity observations are more effective than hydraulic head observations. (4) The importance of flow observations aligned perpendicular to the shoreline varies dramatically depending on distance seaward from the shoreline. Extreme parameter correlation can prohibit unique estimation of permeability parameters such as hydraulic conductivity and flow parameters such as recharge in a density-dependent ground water flow model when using hydraulic head and salinity observations. Adding flow observations perpendicular to the shoreline in areas where ground water is exchanged with the ocean body can reduce the correlation, potentially resulting in unique estimates of these parameter values. Results are expected to be directly applicable to many complex situations, and have implications for model development whether or not formal optimization methods are used in model calibration.
\end{abstract}

\section{Introduction}

Numerical models that account for the effects of fluid density on ground water flow are being used more frequently to address scientific, engineering, and water resource management problems (Voss and Wood 1993; Voss 1999; Voss and Andersson 1993; Simmons et al. 1999; Simmons et al. 2002; Shoemaker and Edwards 2003; Langevin 2001). Also being used more frequently are inverse modeling routines based on nonlinear regression methods documented by Hill (1992, 1998), Hill et al. (2000), Poeter and Hill (1998), and Doherty (1990, 2002).

1U.S. Geological Survey, Florida Integrated Science Center, Center for Water and Restoration Studies, 9100 NW 36th St., Suite 107, Miami, FL 33178; (305) 717-5856; fax (305) 717-5801; bshoemak@ usgs.gov

Received M arch 2003, accepted November 2003.

Published in 2004 by the National Ground Water Association.
However, there has been little application of inverse modeling sensitivity methods to density-dependent ground water flow simulators because of limitations in computing power and the unique technical skills individuals must learn. As computing power increases and expertise grows, modeling studies will likely use both inverse methods and density-dependent ground water flow simulations to solve complicated water resource or ground water contamination problems. Both technologies contain powerful capabilities that can help modelers better understand complex flow systems and make better use of available data.

A practical problem that could benefit from the combined use of these methods is salt water intrusion. Salt water intrusion is important because (1) $70 \%$ of the earth's population lives near a coast, and (2) $\sim 95 \%$ of the earth's water lies in the oceans and seas at high levels of salinity (Freeze and Cherry 1979). To study salt water intrusion, densitydependent ground water flow dynamics are needed to simulate flow in the transition zone between fresh water and salt water. Nonlinear regression methods for calibrating and 
evaluating models offer many advantages over trial and error methods (Hill 1998). For example, in the context of salt water intrusion models, these methods can be used to (1) estimate flow and transport parameter values that provide the best fit to simulated heads, flows, and salinity to their observed equivalents; (2) calculate sensitivity measures for determining the flow and transport parameters most important to reproducing salt water intrusion observations and for assessing whether the observations are sufficient to estimate parameters of interest; and (3) compute measures of parameter and predictive uncertainty.

The work in this paper is partly motivated by a recent salt water intrusion investigation in which inverse modeling methods were applied to a density-dependent ground water flow simulation. In this study, the U.S. Geological Survey (USGS), in cooperation with the South Florida Water Management District (SFWMD), examined the physics of salt water intrusion in southwestern Florida (Shoemaker and Edwards 2003). During this study, the universal inverse modeling routine UCODE (Poeter and Hill 1998) was applied to the flow model to accomplish the following. (1) Identify flow and transport parameters representing aquifer properties and boundary conditions that could not be estimated accurately and uniquely with the available observations. (2) Determine parameter values that produced the best fit between observations and their simulated equivalents. (3) Quantify uncertainty in parameter estimates through linear confidence intervals. In addition, prediction-scaled sensitivities (Hill 1998) suggested that the extent of salt water intrusion, as reflected by salinity predictions, was most affected by recharge, followed in order of declining importance by ground water pumpage, sea level, and the salinity of the Gulf of Mexico. This insight was more quickly and clearly obtained than would have been possible using traditional calibration and sensitivity methods.

The initial success of the combined use of inverse modeling sensitivity methods with a density-dependent ground water flow simulator was encouraging, but motivated further investigation. For example, the SFWMD/ USGS cooperative project did not directly consider potential extreme correlations between flow and transport parameters given observations typically available for calibration of salt water intrusion models. Parameter correlation is measured using correlation coefficients calculated as the covariance between two parameters divided by the product of their standard deviations (Hill 1998). Parameter correlation coefficients with values of +1.00 or -1.00 indicate parameter values that are extremely correlated and generally cannot be estimated uniquely with the observations involved; values $<\sim 0.95$ indicate that unique estimates can likely be obtained.

The purpose of this paper is to investigate what insight and understanding of salt water intrusion calibration problems can be attained by combined use of the sensitivity analysis methods suggested by Hill (1998) with a densitydependent ground water flow simulator, and what numerical difficulties are to be expected. This is accomplished using results from five simulations based on a simple two-dimensional, cross sectional model (Langevin 2001) that represents coastal ground water flow within the transition zone between fresh water and salt water. The five simulations differ in the number and type of observations used to compute sensitivities and correlation coefficients. The simple model and approach also demonstrate (1) some challenges of attempting to calibrate a density-dependent ground water flow model with various types of observations, (2) the relative importance of some flow and transport parameters in simulating the types of quantities commonly observed in coastal aquifer systems, and (3) observation types and locations within the transition zone between fresh water and salt water that provide the most information for estimating important flow and transport parameters. Though a simple model is used for the analysis, results are expected to be applicable to more complex situations because the simple model captures the basic dynamics.

\section{Methods}

Two modeling codes were selected for this study. SEAWAT-2000 (Langevin et al. 2003) was chosen as the density-dependent ground water flow simulator and UCODE (Poeter and Hill 1998) was chosen as the inverse modeling routine.

SEAWAT-2000 is a new version of the SEAWAT program (Guo and Bennett 1998; Guo and Langevin 2002) that combines MODFLOW-2000 (Harbaugh et al. 2000; Hill et al. 2000) and MT3Dms (Zheng and Wang 1999) to solve the coupled ground water flow and solute transport equations. SEAWAT-2000 contains considerably more functionality than the prior release of the code. This code was chosen primarily because it compares well with other density-dependent flow models in terms of accuracy and execution time. In fact, new solvers for the flow equation (Harbaugh et al. 2000; Mehl and Hill 2001) that may reduce model execution times are available. In addition, the model selected for experimentation in this paper (Langevin 2001) was built and run with a prior version of SEAWAT (Guo and Bennett 1998). As such, little reformatting of model input datasets was necessary.

The UCODE inverse modeling routine was used in this study to compute sensitivities and parameter correlation coefficients. MODFLOW-2000 (Hill et al. 2000) capabilities were not used because they do not support the transport parameters and salinity observations being considered. This was a disadvantage because the sensitivities computed by MODFLOW-2000, which uses the sensitivity-equation method, are more accurate than those computed by UCODE, which uses a perturbation approach. The perturbation sensitivities are expected to be sufficiently accurate to produce robust scaled sensitivity measures for evaluating observation and parameter importance. However, Hill and Østerby (2003) show that the less accurate perturbation sensitivities can affect the utility of the correlation coefficients. In particular, values that should be near +1.00 or 1.00 may be smaller in absolute value, so that extreme parameter correlation may not be detected when actually present. Extreme correlation means coordinated linear changes in parameter values would produce the same simulated results at observation locations (Poeter and Hill 1997). In this situation, estimating unique values of extremely correlated parameters using nonlinear regression will likely be 
problematic. Thus, in this work, parameter correlation coefficients that are smaller than +1.00 in absolute value may reflect a lack of correlation, or may reflect the inaccuracies in the perturbation sensitivities. Absolute values that round to +1.00 , however, clearly indicate extreme parameter correlation.

Because calculating and interpreting sensitivities and correlation coefficients are an important part of this paper, the equations that compute these quantities (Hill 1998; Poeter and Hill 1998) are presented here. Dimensionlessscaled sensitivities $\left(s s_{i j}\right)$ are computed as

$$
s s_{i j}=\left.\left(\frac{\partial y_{i}^{\prime}}{\partial b_{j}}\right)\right|_{\underline{b}}\left|b_{j}\right| \omega_{i}^{1 / 2}
$$

where $y_{i}^{\prime}$ is the simulated value associated with the $i$ th observation; $b_{j}$ is the $j$ th estimated parameter; $\left(\partial y_{i}^{\prime} / \partial b_{j}\right)$ is the sensitivity of the simulated value associated with the $i$ th observation with respect to the $j$ th parameter, and is evaluated at the set of parameter values in $\underline{b}$ is a vector that contains parameter values for which the sensitivities are evaluated; and $\omega_{i}$ is the weight of the $i$ th observation.

Dimensionless-scaled sensitivities are used to determine observation types and locations likely to be most effective for estimating a given parameter value. Composite-scaled sensitivities $\left(\right.$ css $\left._{j}\right)$ are computed as

$$
c s s_{j}=\left[\left.\sum_{i=1}^{N D}\left(s s_{i j}\right) 2\right|_{\underline{b}} / N D\right]^{1 / 2}
$$

where $N D$ is the number of observations. Composite-scaled sensitivities are used to determine the relative importance of various flow and transport parameters for reproducing observed values, and as a measure of the amount of information provided by the set of observations for estimating a parameter value. Correlation coefficients, $\operatorname{cor}(i, j)$, are calculated as

$$
\operatorname{cor}(i, j)=\frac{\operatorname{cov}(i, j)}{\operatorname{var}(i)^{1 / 2} \operatorname{var}(j)^{1 / 2}}
$$

where $\operatorname{cov}(i, j)$ is the covariance between parameter $i$ and $j$; $\operatorname{var}(i)$ is the variance of parameter $i$; and $\operatorname{var}(j)$ is the variance of parameter $j$.

Correlation coefficients are used to identify parameters that are extremely correlated given the observations used in experimental simulations.

\section{Experimental Density- Dependent Model and Observations}

The model used in this study was designed to simulate local submarine ground water discharge to Biscayne Bay in southwestern Florida, and is described in detail by Langevin (2001). The model has one row, 149 columns, and 33 layers (Figure 1). Boundary conditions were assigned to the model domain (Figure 1, Table 1) based on general knowledge, field data, and results from some regional ground water models. Boundary conditions include a constant flux of ground water to each cell in column $1(\mathrm{Q} / \mathrm{m})$ representing the general flow of ground water toward the coast that originates from recharge on inland areas not represented by the model grid. The constant-flux was computed using hydraulic conductivities and hydraulic gradients similar to those observed in the Biscayne Aquifer (Merritt 1996; Sonenshein and Koszalka 1996). Net recharge (rch) is applied to the inland portion of layer 1. In the context of this model, net rch is the amount of rainfall that exceeds evapotranspiration and runoff and reaches the water table. Net rch was assigned a reasonable value of 38 $\mathrm{cm} / \mathrm{yr}$ based on studies of rainfall, evapotranspiration, and runoff in a coastal area (Parker et al. 1955; Merritt 1996; German 2000). A no-flow boundary exists along the base of model layer 33 representing a less permeable clastic confining or semiconfining unit that underlies more permeable limestone. This type of hydrostratigraphic sequence is common in coastal environments due to changes in sea level. Constant-head and constant-salinity boundaries are used to represent an ocean body. The constant-head and constant-salinity boundaries were assigned values roughly equal to sea level $(0 \mathrm{~m})$, and the salinity of sea water $(35$ $\mathrm{kg} / \mathrm{m}^{3}$ ), respectively.

Aquifer permeability and transport properties (Table 1) also were assigned to the cross sectional model based on general knowledge, field data, and prior calibration results. These aquifer properties were initially assigned using results from previous studies (Fish and Stewart 1991; Merritt 1996) and were adjusted by Langevin (2001) while calibrating to match hydraulic head and salinity observations. These properties include longitudinal dispersivity, transverse vertical dispersivity, effective porosity, and horizontal and vertical hydraulic conductivity. Diffusion was assumed to be negligible. The model has one stress period, and initial conditions of head and salinity were used to compute a steady-state distribution of hydraulic head, flow, and salinity within the model domain (Figure 2).

An important modification to the model documented in Langevin (2001) was made for the purposes of this study. During preliminary simulations, the implicit finite difference transport solver (GCG) in MT3Dms produced slightly inaccurate solutions due to the time length of transport steps. This time length is computed internally by the program using various stability criteria. The small inaccuracies in the transport solution resulted in large inaccuracies in perturbation sensitivities calculated for horizontal and vertical hydraulic conductivity. Setting the time length of transport steps to 0.5 the value computed by MT3Dms resulted in more accurate transport solutions and perturbation sensitivities. This was confirmed using the highly accurate, mass conservative total-variation-diminishing (TVD) scheme in MT3Dms. With this change in time step length, transport solutions and sensitivities calculated using the GCG solver were essentially the same as those calculated using the TVD scheme. The GCG solver produced results twice as quickly as the TVD solver and therefore was used for the experimental simulations described hereafter.

Hydraulic head, salinity, and flow observations were generated using the final steady-state results from the cross 


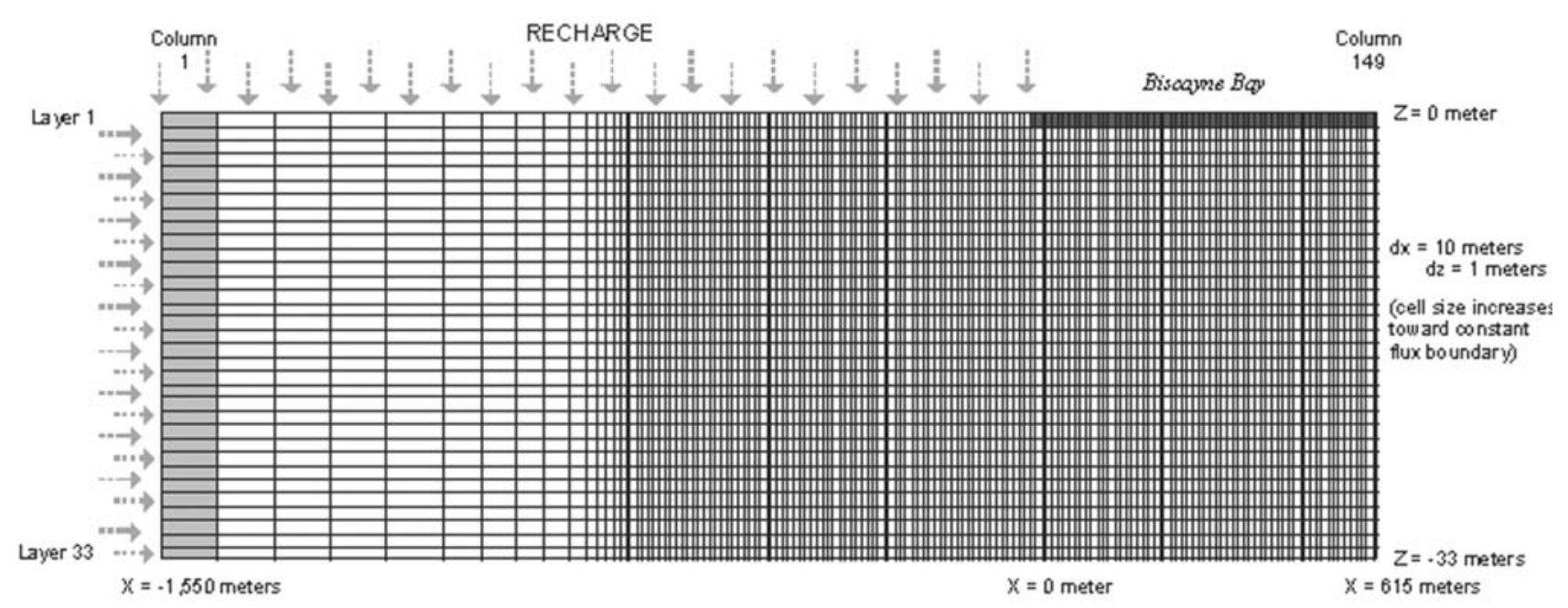

DSTANCE FROMSHORE, IN METERS

EXPLANATION

CONSTANT FLUK BOUNDARY $\square$ CONSTANT HEAD AND CONSTANT CONCENTRATION BOUNDARY

Figure 1. Cross section showing model grid and boundary conditions.

sectional model (Table 2). Measurement error that would likely occur in the field was added to these observations. The measurement error is necessary to calculate the observation weights, which, in turn, are used to calculate the scaled sensitivities and correlation coefficients (weights are used in the calculation of the variance and covariance terms in Equation 3) (Hill 1998). In this study, weights are calculated as the inverse of the variance of likely measurement error. This variance can be computed from the standard deviation or coefficient of variation of measurement error.

For the 23 hydraulic head observations, measurement error was assumed to be normally distributed with a mean of zero (Hill 1992; Cooley 1997) and a standard deviation of $\sim 0.003 \mathrm{~m}$. This standard deviation was based on standard error estimates for water levels measured in wells by the USGS in southern Florida (Prinos et al. 1996). For the 23 salinity observations, measurement error was assumed to be

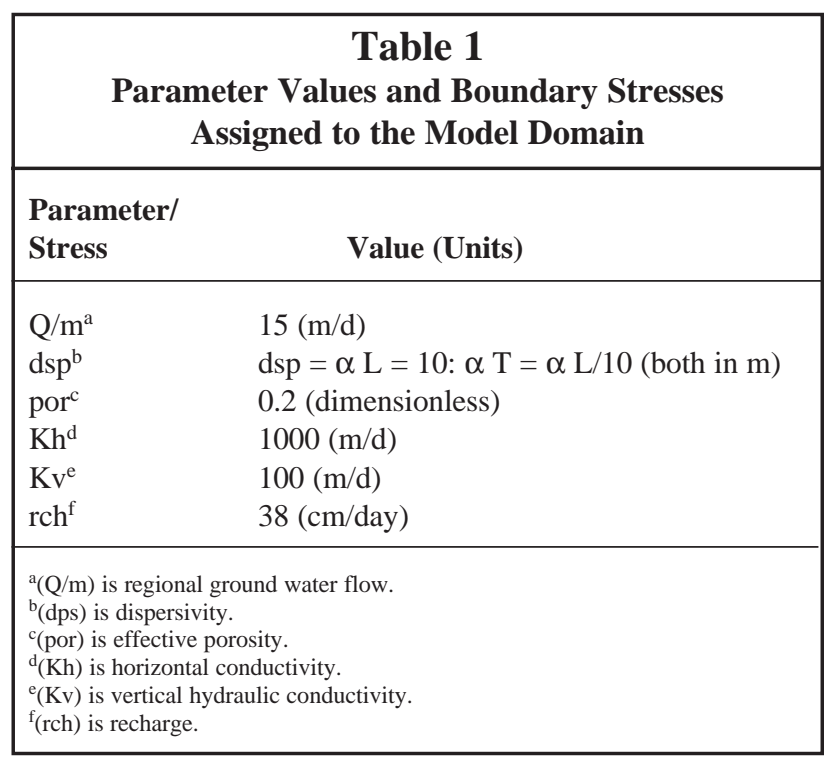

normally distributed with a mean of zero and a standard deviation of $\sim 0.1 \mathrm{~kg} / \mathrm{m}^{3}$. Salinities range from $\sim 3$ to 35 $\mathrm{kg} / \mathrm{m}^{3}$, and for this range using a $0.1 \mathrm{~kg} / \mathrm{m}^{3}$ standard deviation was thought to be appropriate based on discussions with USGS water quality personnel. For the five flow observations, measurement error was assumed to be normally distributed with a mean of zero and a coefficient of variation of $30 \%$. These observations are likely to be obtained by seepage meters, which are known to produce relatively large measurement errors (Shinn et al. 2002). Measurement error was randomly sampled from these distributions and added to the simulated results to create the values used as observations in this work (Table 2). For all of the observations used, the errors imposed may be lower than normally expected in field situations in which many types of errors can occur. Their value relative to one another, however, is thought to be representative of field problems, so that the results of the sensitivity analysis conducted in this work should be applicable to most field studies.

The five experimental simulations differed only by the observations used by UCODE to compute correlation coefficients, dimensionless-scaled sensitivities, and compositescaled sensitivities. The observation sets included 23 hydraulic heads (simulation 1), 23 salinities (simulation 2), 23 hydraulic heads and 23 salinities (simulation 3), 23 hydraulic heads and five flows (simulation 4), and 23 hydraulic heads, 23 salinities, and five flows (simulation 5). All of the observations were located within the transition zone (Figure 3 ) because this region of the flow system has proven to be particularly difficult to understand based on previous studies (Konikow and Reilly 1999).

Execution time is often a problem when considering density-dependent, ground water flow and transport simulations. A single forward run of this simple model required $\sim 30$ min of execution time on a personal computer, with a Pentium II $550 \mathrm{MHz}$ processor and $384 \mathrm{MB}$ RAM. To solve for sensitivities took $\sim 1 \mathrm{~h}$ for each defined parameter. 


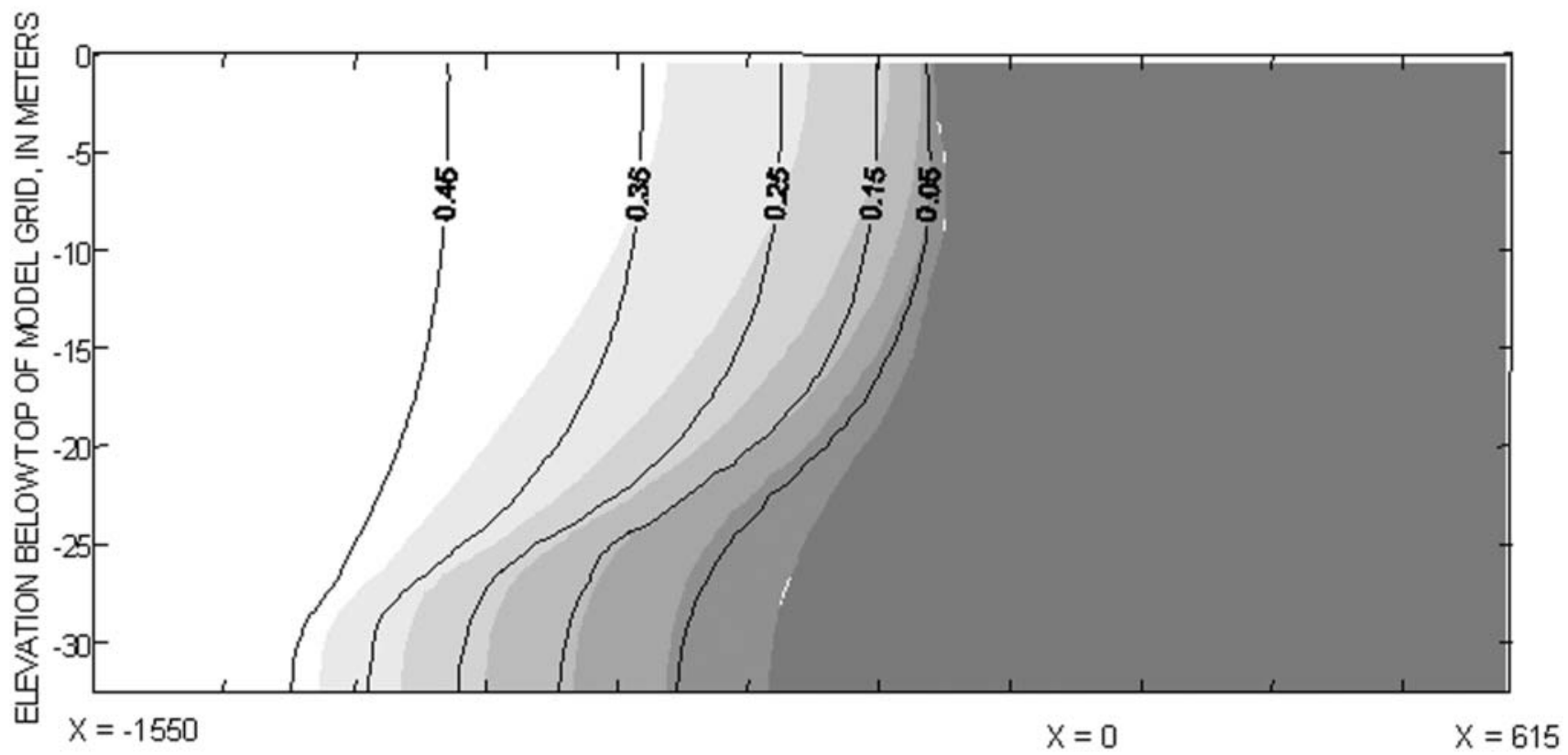

DISTANCE FROM SHORE, IN METERS

EXPLANATION

SIMULATED SALINITY CONCENTRATION, IN KILOGRAMS PER CUBIC METER

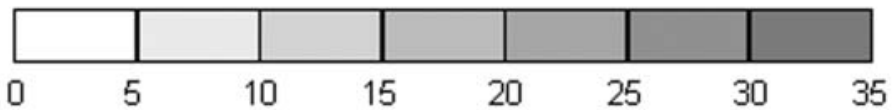

LINE OF EQUAL SIMULATED HYDRAULIC HEAD, IN METERS

Figure 2. Cross section of steady-state hydraulic heads and salinity in the model domain.

Thus, $\sim 6 \mathrm{~h}$ of execution time was necessary for the parameters considered in this paper. To attain this execution time, the longitudinal and vertical components of dispersivity were grouped together by setting the vertical dispersivity equal to 0.1 of the longitudinal dispersivity (Table 1).

Souza and Voss (1987, 1989), Voss and Souza (1998), and Langevin (2001) indicate that simulated hydraulic heads, salinities, and flow are more sensitive to transverse dispersivities (in either the vertical or horizontal directions) than to longitudinal dispersivities because ground water flows mostly parallel to lines of equal solute concentration in the transition zone. The latter makes the density-dependent flow model insensitive to longitudinal dispersivities, but highly sensitive to transverse dispersivities. Additionally, although sea level can be very important for reproducing head, salinity, and flow observations in the transition zone between fresh water and salt water, this parameter is not included. Sea level is typically less uncertain than the other parameters considered in this study (Table 1). For example, sea level and tides are generally well known relative to aquifer properties, recharge, and ground water flow. Composite and dimensionless-scaled sensitivities and correlation coefficients were computed for each experimental simulation for the six parameters listed in Table 1 . The sensitivities were calculated by perturbing the parameter value by $1 \%$ of its value.

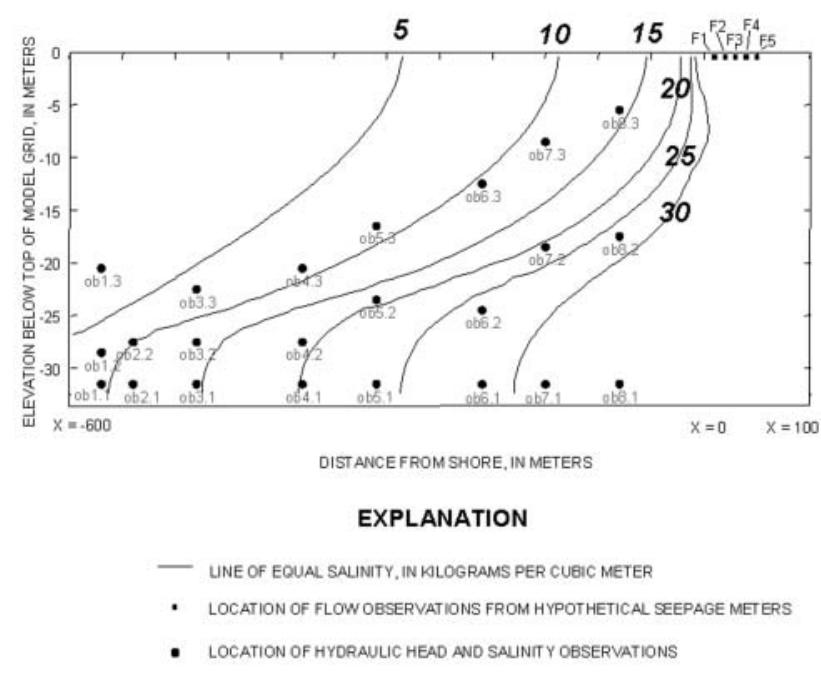

Figure 3. Cross section of observation types and locations in relation to the transition zone between fresh water and salt water.

\section{Results and Discussion}

\section{Composite-Scaled Sensitivities}

Composite-scaled sensitivities for the five experimental simulations are shown in Figure 4. This figure shows that 
Table 2

Observation Types, Locations, Values, and Estimated Measurement Error

\begin{tabular}{|c|c|c|c|c|c|}
\hline Name & Type & Units & $\begin{array}{l}\text { Model } \\
\text { Output }\end{array}$ & $\begin{array}{c}\text { Error } \\
\text { Sample }\end{array}$ & $\begin{array}{c}\text { Observed } \\
\text { Values }\end{array}$ \\
\hline $\mathrm{F} 1$ & Flow & $\mathrm{m}^{3} / \mathrm{d}$ & -136500 & -40967 & -177467 \\
\hline F2 & Flow & $\mathrm{m}^{3} / \mathrm{d}$ & 1470 & -401 & -1871 \\
\hline F3 & Flow & $\mathrm{m}^{3} / \mathrm{d}$ & 61780 & 18595 & 80375 \\
\hline $\mathrm{F} 4$ & Flow & $\mathrm{m}^{3} / \mathrm{d}$ & 86600 & 26033 & 112633 \\
\hline F5 & Flow & $\mathrm{m}^{3} / \mathrm{d}$ & 84920 & 25518 & 110438 \\
\hline ob1.1 & Head & $\mathrm{m}$ & 0.3102 & -0.0009 & 0.3093 \\
\hline ob1.2 & Head & $\mathrm{m}$ & 0.3283 & -0.0004 & 0.3279 \\
\hline ob1.3 & Head & $\mathrm{m}$ & 0.4446 & 0.0035 & 0.4481 \\
\hline ob2.1 & Head & $\mathrm{m}$ & 0.2786 & -0.0006 & 0.2780 \\
\hline ob2.2 & Head & $\mathrm{m}$ & 0.3073 & 0.0045 & 0.3118 \\
\hline ob3.1 & Head & $\mathrm{m}$ & 0.2195 & 0.0028 & 0.2223 \\
\hline ob3.2 & Head & $\mathrm{m}$ & 0.2431 & 0.0081 & 0.2512 \\
\hline ob3.3 & Head & $\mathrm{m}$ & 0.3727 & 0.0012 & 0.3739 \\
\hline ob4.1 & Head & $\mathrm{m}$ & 0.1297 & 0.0014 & 0.1283 \\
\hline ob4.2 & Head & $\mathrm{m}$ & 0.1495 & -0.0037 & 0.1458 \\
\hline ob4.3 & Head & $\mathrm{m}$ & 0.3242 & -0.0005 & 0.3237 \\
\hline ob5.1 & Head & $\mathrm{m}$ & 0.0737 & 0.0004 & 0.0741 \\
\hline ob5.2 & Head & $\mathrm{m}$ & 0.1680 & -0.0009 & 0.1670 \\
\hline ob5.3 & Head & $\mathrm{m}$ & 0.3123 & 0.0037 & 0.3160 \\
\hline ob6.1 & Head & $\mathrm{m}$ & 0.0065 & 0.0007 & 0.0073 \\
\hline ob6.2 & Head & $\mathrm{m}$ & 0.0464 & 0.0006 & 0.0469 \\
\hline ob6.3 & Head & $\mathrm{m}$ & 0.2636 & -0.0004 & 0.2632 \\
\hline ob7.1 & Head & $\mathrm{n}$ & -0.0223 & 0.0035 & -0.0188 \\
\hline ob7.2 & Head & $\mathrm{m}$ & 0.1312 & -0.0006 & 0.1306 \\
\hline ob7.3 & Head & $\mathrm{m}$ & 0.2290 & 0.0045 & 0.2335 \\
\hline ob8.1 & Head & $\mathrm{m}$ & -0.0402 & 0.0028 & -0.0374 \\
\hline ob8.2 & Head & $\mathrm{m}$ & 0.0561 & 0.0081 & 0.0643 \\
\hline ob1.1 & Salinity & $\mathrm{kg} / \mathrm{m}^{3}$ & 11.05 & -0.01 & 11.03 \\
\hline ob1.2 & Salinity & $\mathrm{kg} / \mathrm{m}^{3}$ & 10.26 & 0.10 & 10.36 \\
\hline ob1.3 & Salinity & $\mathrm{kg} / \mathrm{m}^{3}$ & 3.22 & 0.21 & 3.44 \\
\hline ob2.1 & Salinity & $\mathrm{kg} / \mathrm{m}^{3}$ & 12.64 & -0.05 & 12.59 \\
\hline ob2.2 & Salinity & $\mathrm{kg} / \mathrm{m}^{3}$ & 11.40 & -0.06 & 11.38 \\
\hline ob3.1 & Salinity & $\mathrm{kg} / \mathrm{m}^{3}$ & 15.82 & 0.05 & 15.88 \\
\hline ob3.2 & Salinity & $\mathrm{kg} / \mathrm{m}^{3}$ & 14.78 & -0.25 & 14.53 \\
\hline ob3.2 & Salinity & $\mathrm{kg} / \mathrm{m}^{3}$ & 7.17 & 0.04 & 7.21 \\
\hline ob4.1 & Salinity & $\mathrm{kg} / \mathrm{m}^{3}$ & 20.95 & -0.06 & 20.89 \\
\hline ob4.2 & Salinity & $\mathrm{kg} / \mathrm{m}^{3}$ & 19.97 & -0.21 & 19.77 \\
\hline ob4.3 & Salinity & $\mathrm{kg} / \mathrm{m}^{3}$ & 9.48 & 0.03 & 9.51 \\
\hline ob5.1 & Salinity & $\mathrm{kg} / \mathrm{m}^{3}$ & 24.41 & -0.21 & 24.20 \\
\hline ob5.2 & Salinity & $\mathrm{kg} / \mathrm{m}^{3}$ & 19.21 & -0.07 & 19.15 \\
\hline ob5.3 & Salinity & $\mathrm{kg} / \mathrm{m}^{3}$ & 9.18 & 0.07 & 9.24 \\
\hline ob6.1 & Salinity & $\mathrm{kg} / \mathrm{m}^{3}$ & 28.96 & 0.06 & 290.03 \\
\hline ob6.2 & Salinity & $\mathrm{kg} / \mathrm{m}^{3}$ & 26.89 & 0.03 & 26.92 \\
\hline ob6.3 & Salinity & $\mathrm{kg} / \mathrm{m}^{3}$ & 10.76 & 0.16 & 10.92 \\
\hline ob7.1 & Salinity & $\mathrm{kg} / \mathrm{m}^{3}$ & 31.32 & 0.10 & 31.42 \\
\hline ob7.2 & Salinity & $\mathrm{kg} / \mathrm{m}^{3}$ & 21.13 & 0.11 & 21.25 \\
\hline ob7.3 & Salinity & $\mathrm{kg} / \mathrm{m}^{3}$ & 11.48 & 0.24 & 11.71 \\
\hline ob8.1 & Salinity & $\mathrm{kg} / \mathrm{m}^{3}$ & 33.49 & -0.15 & 33.33 \\
\hline ob8.2 & Salinity & $\mathrm{kg} / \mathrm{m}^{3}$ & 26.91 & 0.08 & 26.99 \\
\hline ob8.3 & Salinity & $\mathrm{kg} / \mathrm{m}^{3}$ & 14.24 & -0.03 & 14.21 \\
\hline
\end{tabular}




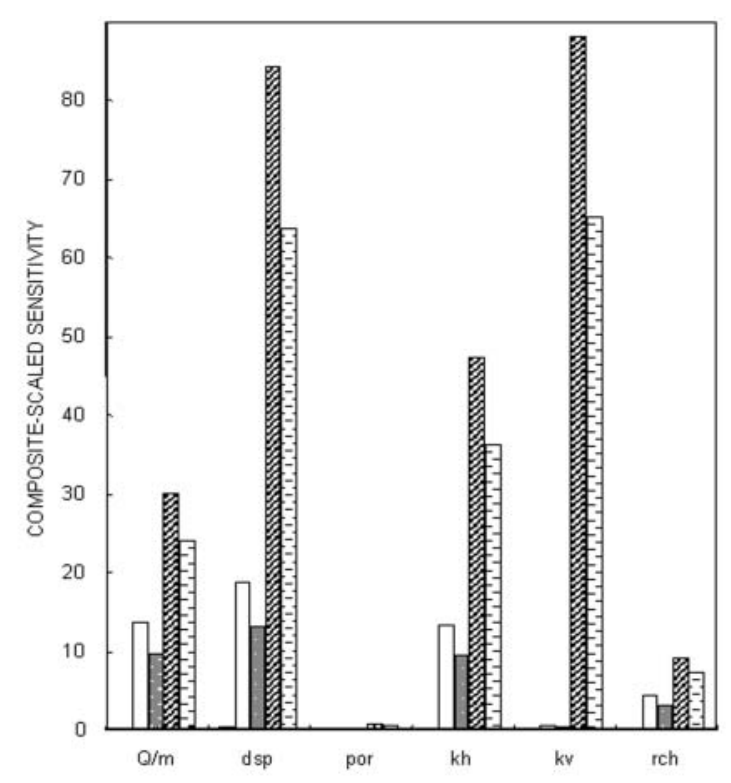

$(\mathrm{Q} / \mathrm{m})$ is regional ground water flow. (dsp) is dispersivity. (por) is effective porosity. (kh) is horizontal hydraulic conductivity. $(k v)$ is vertical hydraulic conductivity. ( $\mathrm{rch}$ ) is recharge.

\section{EXPLANATION}

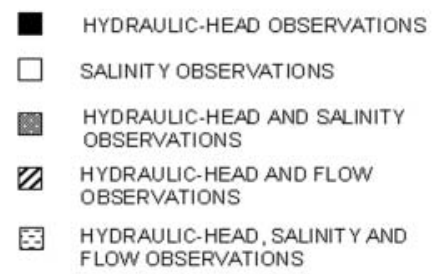

Figure 4. Bar graph of composite-scaled sensitivity for each experimental simulation.

the hydraulic head observations alone provide little information about any of the model parameters. When salinity observations are included (experimental simulations 2 and 3), a consistent pattern is evident. Dispersivity is most important, followed by regional ground water flow, horizontal hydraulic conductivity, recharge, vertical hydraulic conductivity, and effective porosity. Vertical hydraulic conductivity becomes the most important parameter in experimental simulations 4 and 5, which use flow observations. This means the flow observations provide substantial information about vertical hydraulic conductivity.

Dispersivity is clearly a very important parameter in this study, being either the most sensitive or second most sensitive when flow observations are used in the analysis. The importance of dispersivity to the different type of observations is discussed next using dimensionless-scaled sensitivities.

\section{Dimensionless- Scaled Sensitivities}

Dimensionless-scaled sensitivities for dispersivity are plotted in Figure 5. Two aspects of these results are discussed in the following sections-(1) the implications of a positive or negative dimensionless-scaled sensitivity value, and (2) observation locations and types likely to be most effective for estimating dispersivity.
Sign Implications of Dimensionless-Scaled Sensitivities

Dimensionless-scaled sensitivities of hydraulic head observations to dispersivity are all positive (Figure 5), meaning that increasing dispersivity increases heads and decreasing dispersivity decreases heads. This reflects the underlying physics. Increasing dispersivity increases the process of salt water mixing with fresh water. This causes the salt water to become less dense and to rise toward the sea, and causes the transition zone to be more vertically oriented and to have a somewhat broader top and a much less pronounced "toe" (Figure 6a). The latter allows more fresh water from recharge to move seaward, resulting in higher hydraulic heads in the vicinity of observation locations. Decreasing dispersivity decreases the mixing process, which produces a much more pronounced salt water toe and allows less fresh water from recharge to move seaward (Figure 6b), resulting in lower hydraulic heads in the vicinity of observation locations.

Dimensionless-scaled sensitivities of salinity observations to dispersivity are negative in most of the transition zone and are positive only at the top of the seaward part of the zone (Figure 5). This means increasing dispersivity decreases salinity in most of the transition zone and increases salinity at the top of the transition zone. Conversely, decreasing dispersivity increases salinity in most of the transition zone and decreases salinity at the top of the transition zone. These changes in salinity are explained by the flow system responses to the changes in dispersivity as shown in Figure 6 and described in the prior paragraph.

Dimensionless-scaled sensitivities of flow observations to dispersivity are mostly negative (Figure 5). An exception is flow observation F5, which has a positive sensitivity. Table 3 was designed to help explain the sign implications of these dimensionless-scaled sensitivities. For clarity, only the implications and results of increasing dispersivity are discussed in this paragraph. When the dimensionless-scaled sensitivity is negative and ground water is discharging to the sea (flow observations F1 and F2), increasing dispersivity increases the amount of ground water discharge. When the dimensionless-scaled sensitivity is negative and sea water is flowing into the aquifer (flow observations F3 and F4), increasing dispersivity decreases the amount of sea water inflow. When the sensitivity is positive and sea water is flowing into the aquifer (flow observation F5), increasing dispersivity increases in the amount of sea water inflow.

\section{Effective Observation Locations for Estimating Dispersivity}

Dimensionless-scaled sensitivity of hydraulic head observations to dispersivity range from 0.01 in the top third of the transition zone to 0.52 toward the toe of the transition zone (Figure 5). This result indicates that hydraulic head observations located toward the toe of the transition zone provide more information for estimating dispersivity than head observations located in the middle or top third of the transition zone. The control exerted by the sea, as simulated by the constant-head boundary condition in Biscayne Bay (Figure 1), probably explains this trend in sensitivity. Dimensionless-scaled sensitivities near this boundary are low because the constant heads prevent 


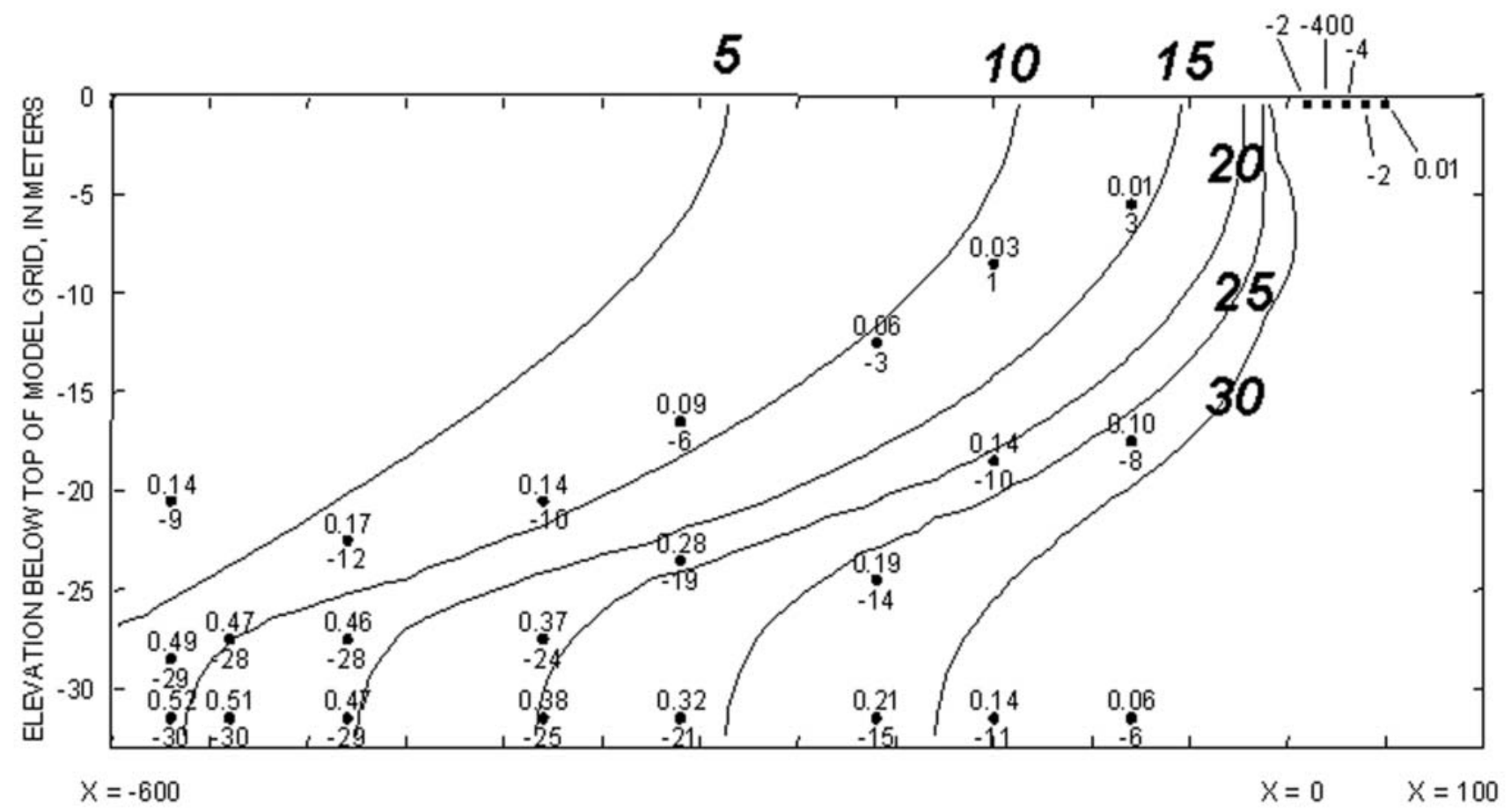

DISTANCE FROM SHORE, IN METERS

\section{EXPLANATION}

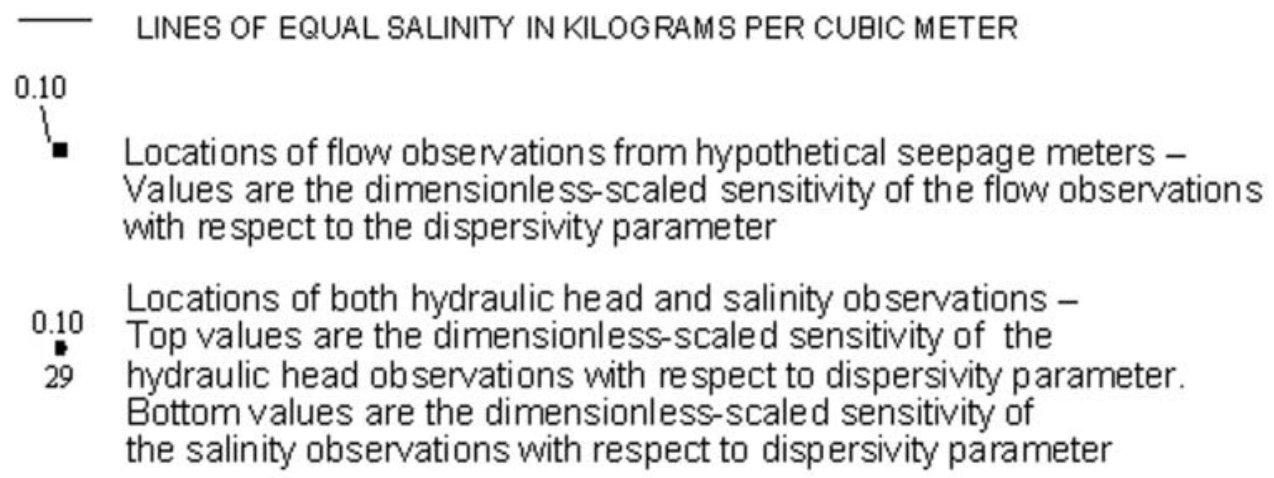

Figure 5. Cross section of dimensionless-scaled sensitivities for dispersivity.

simulated heads from changing when dispersivity is perturbed from an initial value.

Dimensionless-scaled sensitivity of salinity observations to dispersivity range from +3 to -30 (Figure 5). The large absolute values in the toe of the transition zone between fresh water and salt water suggest salinity observations in this location are most effective for estimating dispersivity. This evidence is consistent in that the toe of the transition zone seems most volatile in response to changing dispersivity values (Figure 6). For example, small values of dispersivity result in a toe of the transition zone that moves farther inland. Conversely, large values of dispersivity result in a toe of the transition zone that moves farther seaward. The top third of the transition zone changes only slightly with different values of dispersivity because of the control exerted by the sea, represented as a constant-concentration boundary condition (Figure 1).
Dimensionless-scaled sensitivities of flow observations to dispersivity range from-400.0 to +0.01 (Figure 5). In this model, flow observations within $\sim 50$ m of the coastline are most effective for estimating dispersivity (Figure 7). In other coastal aquifer systems, the distance would depend on the distance over which flow to the ocean diminished. This often can be evaluated using temperature sensors or by preliminary flow measurements or modeling. The large differences in the dimensionless-scaled sensitivities for the flow observations can be partly explained by the weights for these observations (recall from Equation 1 that the square root of the weight, $\mathrm{w}^{1 / 2}$, is a term in the calculation of dimensionless-scaled sensitivity). This is illustrated using flow observations F1, F2, and F3. Table 3 shows that when dispersivity is increased to 10.1 from the base case value of 10.0, the magnitude of flow change is about the same at F1, F2, and F3, meaning that the sensitivity dy/db 
Table 3

Changes in Flow Caused by Changes in the Dispersion Parameter

\begin{tabular}{|c|c|c|c|c|c|}
\hline \multicolumn{6}{|l|}{$\mathrm{dsp}=9.9$} \\
\hline Flow Observation & F1 & F2 & F3 & F4 & F5 \\
\hline Flow change & $\sim 1 \%$ less & $\sim 85 \%$ less & $\sim 2 \%$ more & $\sim 0.5 \%$ more & Very small decrease \\
\hline Direction of flow & Discharge to sea & Discharge to sea & Flow into aquifer & Flow into aquifer & Flow into aquifer \\
\hline \multicolumn{6}{|l|}{ dsp $=10.0($ base case $)$} \\
\hline Flow $\left(\mathrm{m}^{3} / \mathrm{d}\right)$ & $-136,500$ & -1470 & 61,780 & 86,600 & 84,920 \\
\hline $\begin{array}{l}\text { Dimensionless-scalec } \\
\text { sensitivity value }\end{array}$ & -2 & -400 & -4 & -2 & 0.01 \\
\hline \multicolumn{6}{|l|}{$\mathrm{dsp}=10.1$} \\
\hline Flow Observation & F1 & F2 & F3 & F4 & F5 \\
\hline Flow change $(\%)$ & $\sim 1 \%$ more & $\sim 85 \%$ more & $\sim 2 \%$ less & $\sim 0.5 \%$ less & Very small increase \\
\hline Flow change $\left(\mathrm{m}^{3} / \mathrm{d}\right)$ & 1220 & 1250 & 1080 & 430 & -6 \\
\hline $\begin{array}{l}\text { Direction of } \\
\text { flow }\end{array}$ & $\begin{array}{l}\text { Discharge } \\
\text { to sea }\end{array}$ & $\begin{array}{l}\text { Discharge } \\
\text { to sea }\end{array}$ & $\begin{array}{l}\text { Flow into } \\
\text { aquifer }\end{array}$ & $\begin{array}{l}\text { Flow into } \\
\text { aquifer }\end{array}$ & $\begin{array}{l}\text { Flow into } \\
\text { aquifer }\end{array}$ \\
\hline
\end{tabular}

is about the same for each of the three observations. However, the dimensionless-scaled sensitivity at F2 is much larger than that at F1 or F3 because of the differences in the weights for these observations. These differences in the weights are related to differences in the magnitudes of observed flows at the three locations. Weights for the flows were defined using coefficients of variation (equal to 0.3 ), which means that each weight is inversely proportional to the magnitude of the observed flow. For example, the dis-

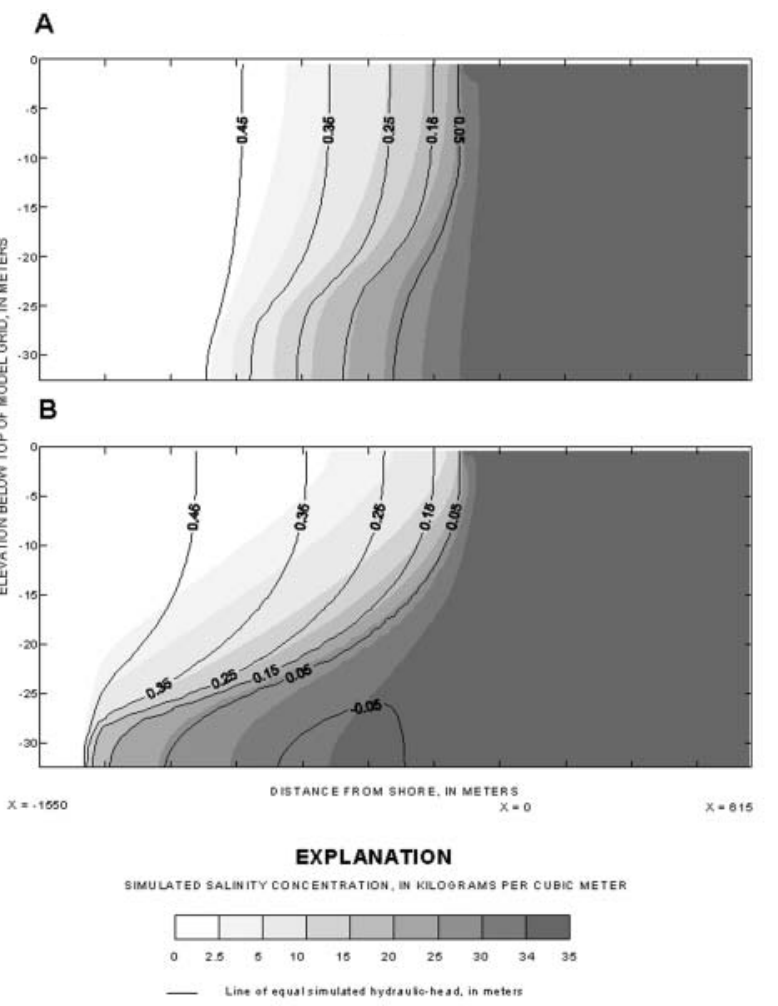

Figure 6. Cross sections showing the change in the geometry of the transition zone resulting from changes in the dispersivity parameter. The dispersivity parameter equals $15 \mathrm{~m}$ in cross section (a), and $5 \mathrm{~m}$ in cross section (b). charge to the sea at F1 is $136,500 \mathrm{~m}^{3} / \mathrm{d}$ (Table 3 ), and $\mathrm{w}^{1 / 2}$ for $\mathrm{F} 1$ is thus equal to $1 /\left(0.3 \times 136,500 \mathrm{~m}^{3} / \mathrm{d}\right)=0.000024$ $\mathrm{d} / \mathrm{m}^{3}$. The discharge to the sea at F2 is $1470 \mathrm{~m}^{3} / \mathrm{d}$ (Table 3), and $\mathrm{w}^{1 / 2}$ is thus equal to $1 /\left(0.3 \times 1470 \mathrm{~m}^{3} / \mathrm{d}\right)=0.0023$ $\mathrm{d} / \mathrm{m}^{3}$. Thus, the difference in the $\mathrm{w}^{1 / 2}$ term for these two observations is clearly the primary reason for the differences in the dimensionless-scaled sensitivity.

This analysis of the effect of the weights on the dimensionless-scaled sensitivity values also is applicable when considering the importance of the different flow observations in the context of calibrating this model using weighted least-squares regression. The weighting used would cause the F2 observation to have a greater influence in the regression and, thus, a greater influence on the estimated model parameter values compared to the observations at F1 and F3.

Although the weights clearly have a large influence on the relative importance of different flow observations, it is important to also consider the magnitudes of the changes in flux in response to a change in dispersivity when determining flow observation importance. For the five different flow observations considered in this study, these changes in flux suggest that observations at, and just landward of, the flow reversal location are likely to be most important to estimating dispersivity values.

\section{Observation Types Likely to Be Important for Estimating Dispersivity}

Examining the absolute magnitude of observation dimensionless-scaled sensitivities to dispersivity can give some insight into the observation types likely to be most effective for estimating dispersivity. Figure 5 shows that salinity observations are always more important than hydraulic head observations. Flow observations near the coastline can be effective, but observations too far from shore are ineffective for estimating dispersivity (Figure 7). As previously mentioned for this model, flow observations within $\sim 50 \mathrm{~m}$ of the coastline and near the flow reversal zone appear to be most effective for estimating dispersivity. In other coastal aquifer systems, the locations of important 


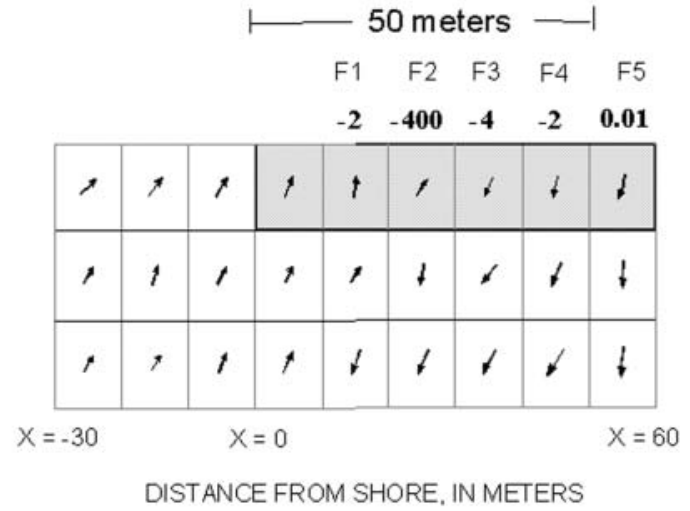

EXPLANATION

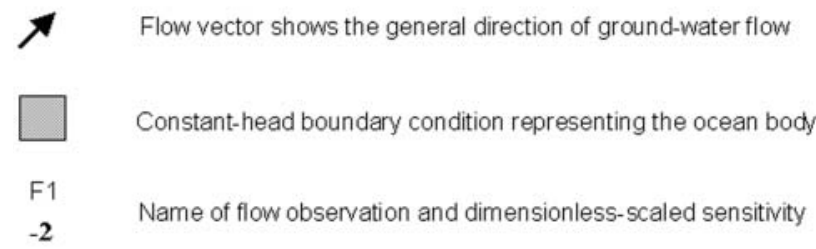

Figure 7. Cross section of the location and dimensionlessscaled sensitivity of flow observations in relation to ground water flow directions.

flow observations would likely depend on the magnitudes and variability of fluxes near the coastline.

\section{Parameter Correlation Coefficients}

Parameter correlation coefficients for six parameters in the five experimental simulations were calculated. The absolute values of the correlations for all parameter pairs were $<0.85$ for all observation sets. The correlation coefficient for horizontal hydraulic conductivity and regional ground water flow was 0.84 when salinity observations (simulation 2) or hydraulic head and salinity observations (simulation 3) were used.

It is already well established that hydraulic-conductivity parameters and flow parameters representing, for example, recharge or ground water pumpage are correlated when calibrating a density-independent flow model solely using hydraulic head observations (Hill et al. 1998; Emsellem and de Marsily 1971). Therefore, the questions arise as to whether the hydraulic-conductivity and flow parameters are correlated in this density-dependent flow model when using solely hydraulic head observations, and how salinity observations affect the correlations. That is, are the calculated correlation coefficients reliably identifying all extreme parameter correlations in this problem? As previously mentioned, UCODE computes perturbation sensitivities that are less accurate than, for example, the derivative sensitivities computed by MODFLOW-2000. This loss of accuracy may produce unreliable correlation coefficients.

To test this concern, the model was run again with both hydraulic-conductivity and flow parameters in Table 1 multiplied by 100 . The simulated heads and salinities in this additional scenario were the same as those in the baseline model (Figure 2). This means that if only head and/or salinity observations are available for calibration, these perme- ability and flow parameters are extremely correlated. In other words, 100 times more water flowing through a system that is 100 times more permeable produces the same simulated head and salinity results. This is consistent with the small sensitivity of all observations to porosity (Figure 4) as follows. Density would only affect the correlation between the hydraulic conductivity and flow parameters if the salinities were sensitive to the flow rate. This dependence would be indicated by a sensitivity of salinity to porosity. The result shown in Figure 4-that the sensitivity of salinity to porosity is very small relative to its sensitivity to the other parameters-indicates insensitivity to velocity.

In density-independent models, previous research suggests flow observations are useful for dramatically reducing extreme correlations between conductivity and flow parameters (Poeter and Hill 1998; Emsellem and de Marsily 1971; Barth and Hill in review). Apparently, flow observations serve the same role in density-dependent models. As previously mentioned, the correlation coefficient for hydraulic conductivity and ground water flow was $\sim 0.84$ when solely using salinity observations, or using hydraulic head and salinity observations. The value of these coefficients changed to- 0.17 and 0.79 , respectively, when flow observations were included in simulations 4 and 5 . This suggests flow observations reduce correlation for this parameter pair. The prior statement is confirmed by results of running the model with both hydraulic-conductivity and flow parameters multiplied by 100 . In this additional scenario, simulated flows at observation locations were $\sim 100$ times larger in absolute value than simulated flows in the baseline scenario. The hydraulic heads and salinities were basically the same.

\section{A Short Note on Nonlinearity}

This density-dependent flow model was nonlinear with respect to the dispersivity parameter in the transition zone between fresh water and salt water. In other words, parameter sensitivities and correlation coefficients changed with different values for dispersivity. For example, when using hydraulic head, salinity, and flow observations, while setting the dispersivity parameter equal to $15 \mathrm{~m}$, the composite scaled sensitivities of effective porosity, ground water flow, and dispersivity are $\sim 0.887,27.6$, and 9.77 , respectively. When the dispersivity parameter is set equal to $5 \mathrm{~m}$, the composite scaled sensitivities of effective porosity, ground water flow, and dispersivity are $\sim 2.28,16.5$, and 58.4, respectively. The largest change in composite-scaled sensitivity occurred for the dispersivity parameter.

Apparently, the conclusions about preferable observation locations and types are robust in the presence of the nonlinearity in dispersivity. Simulations that were run with the dispersivity parameter set equal to $15 \mathrm{~m} / \mathrm{d}$ and $5 \mathrm{~m} / \mathrm{d}$ support this statement. Despite the dispersivity changes, dimensionless-scaled sensitivities still suggested that when estimating dispersivity: (1) hydraulic-head and salinity observations located in the toe of the transition zone are most favorable; (2) salinity values provide more information than hydraulic-head observations; and (3) flow observations located just landward of the area where the flow direction reverses at the bottom of the ocean are most effective. 


\section{Conclusions}

A sensitivity analysis with a density-dependent ground water flow simulator was conducted to produce insight and understanding of salt water intrusion calibration problems. The approach used here clearly and defensibly shows (1) the relative importance of various flow and transport parameters for reproducing hydraulic head, salinity, and flow observations, (2) observation locations and observation types likely to be most effective for estimating a dispersivity parameter, (3) parameters that may not be uniquely estimated with a given set of observations because of extreme parameter correlation, and (4) the types of observations that may reduce correlation between parameter values and encourage unique estimates. These results were obtained for the transition zone between fresh water and salt water, a natural feature of coastal ground water flow systems that has previously proven to be very difficult to model and understand. The results apply regardless of how model calibration is pursued; that is, observations provide the same amount of information whether using gradient, global search, or manual trial-and-error methods. The methods investigated here clearly show the information provided by observations.

The following more specific conclusions can be drawn from this study.

1. Dispersivity was a very important parameter for reproducing the distribution of hydraulic head, salinity, and flow in the transition zone between fresh water and salt water, as indicated by composite-scaled sensitivities. It is expected that dispersivity is equally important in many field investigations.

2. The toe of the transition zone between fresh water and salt water, and areas near the coastline where submarine ground water discharge occur, are effective locations for (a) hydraulic head and salinity observations, and (b) flow observations collected on the ocean bottom with, for example, seepage meters. For layered systems in which toes occur at the base of multiple permeable layers, each of the toe locations is likely to be important.

3. Salinity observations are more effective than hydraulic head observations for estimating important dispersivity parameter values in the transition zone between fresh water and salt water. For the same purpose, flow observations located within or near areas of submarine ground water discharge are most effective. Flow observations located just landward of the area where the flow direction reverses at the bottom of the ocean (to the sea vs. from the sea) appear to be most effective for estimating important dispersivity parameter values. Flow observations located farther offshore generally are not useful.

4. As in density-independent models, flow parameters and permeability parameters were extremely correlated when calibrating this density-dependent model solely to hydraulic head and salinity observations. Adding flow observations perpendicular to the shoreline in areas where ground water is exchanged with the ocean reduced the correlation, potentially resulting in unique estimates of these parameter values.
5. The density-dependent flow model was nonlinear with respect to the dispersivity parameter. Thus, different values for dispersivity resulted in different parameter sensitivities and correlations. However, the conclusions about preferable observation locations and types were robust in the presence of the nonlinearity in dispersivity studied here.

\section{Acknowledgments}

This article was mostly inspired through collaborate development of research proposals with Mary Hill (USGS, Boulder, Colorado) and Matthew Ely (USGS, Tacoma, Washington). Paul Barlow (USGS, Reston, Virginia) provided support and guidance. This work was funded in part by the USGS Office of Ground Water in Reston, Virginia, and is an extension of work funded by the SFWMD and the USGS Cooperative Work Program in Miami, Florida. Raul Patterson and Chris Langevin (USGS, Miami, Florida) developed the cross section model used for experimental simulations. Mary Hill, Eve Kuniansky and Sandy Cooper (both with USGS, Norcross, Georgia), Rhonda Howard and Mike Deacon (both with USGS, Miami, Florida), and Matthew Tonkin (S.S. Papadopulos and Associates Inc.) generously reviewed initial drafts. Claire Tiedeman (USGS, Menlo Park, California) and one anonymous reviewer for Ground Water also provided many insightful comments.

Editor's Note: The use of brand names in peer-reviewed papers is for identification purposes only and does not constitute endorsement by the author, his employer, or the National Ground Water Association.

\section{References}

Barth, G., and M.C. Hill. In review. Parameter and observation importance in modeling virus transport in saturated systems-Investigations in one and two dimensions.

Cooley, R.L. 1997. Confidence intervals for ground water models using linearization, likelihood, and bootstrap methods. Ground Water 35, no. 5: 869-880.

Doherty, J. 1990. MODINV-Suite of Software for MODFLOW Preprocessing, Postprocessing, and Parameter Optimization User's Manual. Queensland, Australia: Australian Centre for Tropical Freshwater Research, James Cook University.

Doherty, J. 2002. PEST-Model independent parameter estimation, version 6. Queensland, Australia: Watermark Numerical Computing.

Emsellem, Y., and G. de Marsily. 1971. An automated solution for the inverse problem. Water Resources Research 7, no. 5: 1264-1283.

Fish, J.E., and M. Stewart, 1991. Hydrogeology of the surficial aquifer system, Dade County, Florida. U.S. Geological Survey Water Resources Investigations Report 90-4108.

Freeze, A.R., and J.A. Cherry. 1979. Groundwater. Englewood Cliffs, New Jersey: Prentice Hall.

German, E.R. 2000. Regional evaluation of evapotranspiration in the Everglades. U.S. Geological Survey Water Resources Investigations Report 00-4217.

Guo, W., and G.D. Bennett. 1998. SEAWAT version 1.1-A computer program for simulations of ground water flow of variable density. A report prepared by Missimer International Inc. 
Guo, W., and C.D. Langevin. 2002. User's guide to SEAWAT: A computer program for simulation of three-dimensional variable-density ground water flow. U.S. Geological Survey Open-File Report 01-434.

Harbaugh, A.W., E.R. Banta, M.C. Hill, and M.G. McDonald. 2000. MODFLOW-2000, the U.S. Geological Survey modular ground water model-User guide to modularization concepts and the ground water flow process. U.S. Geological Survey Open-File Report 00-92.

Hill, M.C. 1992. A computer program (MODFLOWP) for estimating parameters of a transient, three-dimensional, ground water flow model using non-linear regression. U.S. Geological Survey Open File Report 91-484.

Hill, M.C. 1998. Methods and guidelines for effective model calibration. U.S. Geological Survey Water-Resources Investigations Report 98-4005.

Hill, M.C., E.R. Banta, A.W. Harbaugh, and E.R. Anderman. 2000. MODFLOW-2000, the U.S. Geological Survey modular ground water model-User guide to the observation, sensitivity, and parameter estimation processes and three post processing programs. U.S. Geological Survey Open File Report 00-184.

Hill, M.C., and O. Østerby. 2003. Determining extreme parameter correlation in ground water models. Ground Water 41, no. 4: 420-430.

Konikow, L.F, and T.E. Reilly. 1999. Seawater intrusion in the United States. In Seawater Intrusion in Coastal AquifersConcepts, Methods, and Practices, ed. J. Bear, A.H.-D. Cheng, S. Sorek, D. Ouazar, and I Herrera. Dordrecht, Netherlands: Kluwer Academic Publishers.

Langevin, C.D. 2001. Simulation of ground water discharge to Biscayne Bay, southeastern Florida. U.S. Geological Survey Water-Resources Investigations Report 00-4251.

Langevin, C.D., W.B. Shoemaker, and W. Guo. 2003. MODFLOW-2000, the U.S. Geological Survey modular groundwater model-Documentation of the SEAWAT-2000 version with the variable density flow process (VDF) and the integrated MT3Dms transport process (IMT). U.S. Geological Survey Open-File Report 03-426.

Mehl, S.W., and M.C. Hill. 2001. MODFLOW-2000, the U.S. Geological Survey modular ground water model-User guide to the link-AMG (LMG) package for solving matrix equations using an algebraic multigrid solver. U.S. Geological Survey Open-File Report 01-177.

Merritt, M.L. 1996. Simulation of the water table altitude in the Biscayne Aquifer, southern Dade County, Florida, water years 1945-89. U.S. Geological Survey Water-Supply Paper 2458.

Parker, G.G., G.E. Ferguson, and S.K. Love. 1955. Water resources of southeastern Florida. U.S. Geological Survey Water-Supply Paper 1255.

Poeter, E.P., and M.C. Hill. 1997. Inverse models: A necessary next step in ground water modeling. Ground Water 35, no. 2: 250-260.

Poeter, E.P., and M.C. Hill. 1998. Documentation of UCODE, a computer code for universal inverse modeling. U.S. Geological Survey Water-Resources Investigations Report 98-4080.

Prinos, S., T. Richards, and R. Krulikas. 1996. Water resources data Florida water year 1996. U.S. Geological Survey Water-Data Report FL-96-2B.
Shoemaker W.B., and K.M. Edwards. 2003. Potential for saltwater intrusion into the lower Tamiami Aquifer near Bonita Springs, southwestern Florida. U.S. Geological Survey Water-Resources Investigation Report 03-4262.

Shinn E.A., C.D. Reich, D. Hickey, and A. Tihansky. 2002. Geology and hydrology of the Florida Keys: Ground water flow and seepage. Abstract presented on the South Florida Information Access web page, http://sofia.usgs.gov/projects/grndwtr_flow/grflowab1.html.

Simmons, C.T., J.M. Sharp Jr., and N.I. Robinson. 1999. Density-driven free convection in zones of inverted salinity through fractured low permeability units in the Gulf of Mexico Basin, Texas, USA. In Proceedings of the Water 99 Joint Congress, July 6-8, Brisbane, Queensland, Australia. Australia: Institute of Engineers.

Simmons, C.T., K.A. Narayan, J.A. Woods, and A.L. Herczeg. 2002. Ground water flow and solute transport at the Mourquong saline-water disposal basin, Murray Basin, southeastern Australia. Hydrogeology Journal 10, 278-295.

Sonenshein, R.S., and E.J. Koszalka. 1996. Trends in the water table altitude (1984-93) and salt water intrusion (1974-93) in the Biscayne Aquifer, Dade County, Florida. U.S. Geological Survey Open-File Report 95-705.

Souza, W.R., and C.I. Voss. 1987. Analysis of an anisotropic coastal aquifer system using a variable-density flow and solute transport simulation. Journal of Hydrology 92, $17-41$.

Souza, W.R., and C.I. Voss. 1989. Assessment of potable ground water in a fresh water lens using a variable-density flow and solute transport simulation. In Proceedings of the NWWA Conference on Solving Ground Water Problems with Models, February 7-9, 1989, Indianapolis, Indiana. Dublin, Ohio: National Water Well Association.

Voss, C.I. 1999. USGS SUTRA code-History, practical use, and application in Hawaii. In Seawater Intrusion in Coastal Aquifers-Concepts, Methods, and Practices, ed. J. Bear, A.H.-D. Cheng, S. Sorek, D. Ouazar, and I Herrera. Dordrecht, Netherlands: Kluwer Academic Publishers.

Voss, C.I., and J. Andersson. 1993. Regional flow in the Baltic Shield during Holocene coastal regression. Ground Water 31, no. 6: 989-1006.

Voss, C.I., and W.R. Souza. 1998. Dynamics of a regional fresh water-salt water transition zone in an anisotropic coastal aquifer system. U.S. Geological Survey Open-File Report 98-398.

Voss, C.I., and W.W. Wood. 1993. Synthesis of geochemical, isotopic, and ground water modeling analysis to explain regional flow in a coastal aquifer of southern Oahu, Hawaii. In Proceedings of the International Atomic Energy Agency Final Research Coordination Meeting, June 1-4, Vienna, Austria, 147-178. Vienna, Austria: International Atomic Energy Agency.

Zheng, C., and P.P. Wang. 1999. MT3Dms-A modular threedimensional multispecies transport model for simulation of advection, dispersivity and chemical reactions of contaminants in ground water systems: Documentation and user's guide. U.S. Army Corps of Engineers Contract Report SERDP-99-1. 